Approved for public release

distribution is unlimited.

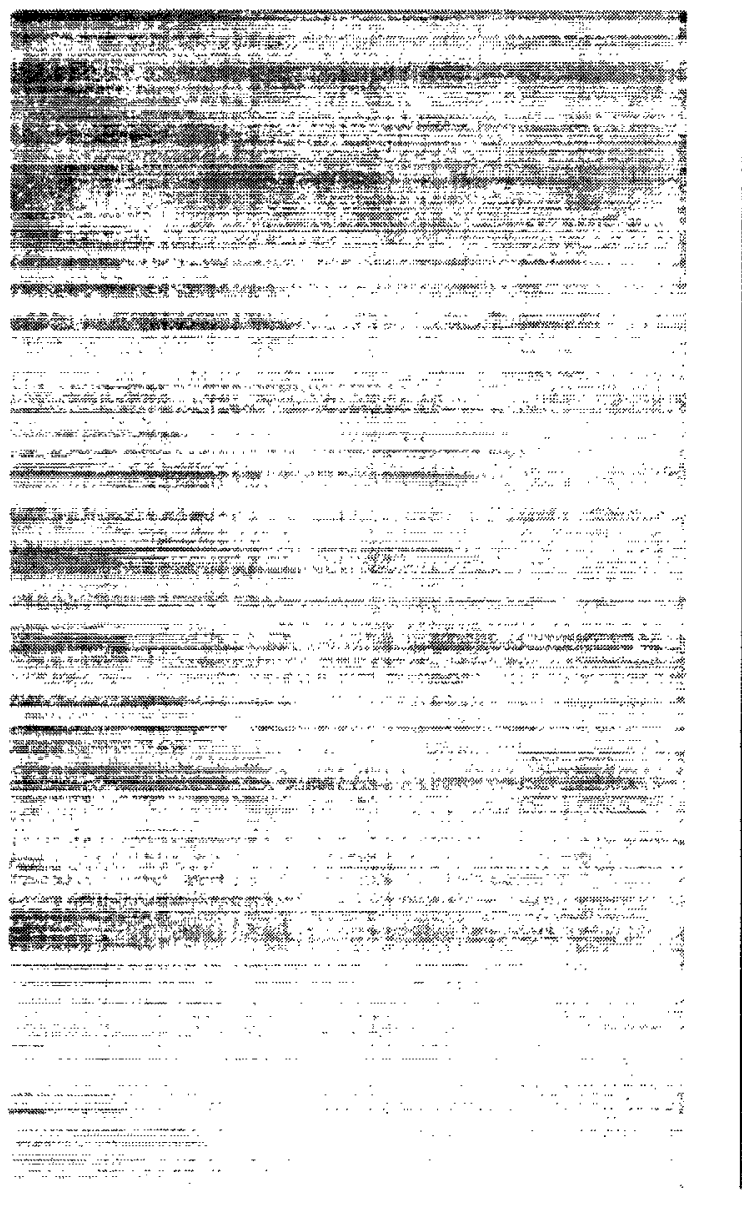

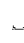

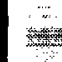


Prepared by Lanny Piotrowski, Group EES-1

An Affirmative Action/Equal Opportunity Employer

This report was prepared as an account of work sponsored by an agency of the United States Government. Neither The Regents of the University of California, the United States

Government nor any agency thereof, nor any of their errployees, makes any warranty, express or implied, or assumes any legal liability or responsibility for the accuracy, completeness, or usefulness of any information, apparatus, product, or process disclosed, or represents that its use would not infringe privately owned rights. Reference herein to any specific commercial product, process, or service by trade name, trademark, mantufacturer, or otherwise, does not necessarily constitute or imply its endorsement, recommendation, or favoring by The Regents of the University of California, the United States Government, or any agency thereof. The vierus and opinions of authors expressed herein do not necessarily state or reflect those of The Regents of the University of California, the United States Government, or any agency thereof. Los Alamos National Laboratory strongly supports academic freedom and a researcher's right to publish; as an institution, however, the Laboratory does not endorse the viewpoint of a publication or guarantee its technical correctness. 


\section{DISCLAIMER}

Portions of this document may be illegible in electronic image products. Images are produced from the best available original document. 
Geochemistry of Sediment Samples at TA-54, Los Alamos National Laboratory

Katherine Campbell

Steven L. Reneau 


\title{
GEOCHEMISTRY OF SEDIMENT SAMPLES AT TA-54, LOS ALAMOS NATIONAL LABORATORY
}

by

Katherine Campbell and Steven L. Reneau

\begin{abstract}
A statistical evaluation of sediment data from Technical Area 54, Los Alamos National Laboratory, was used to examine the relation of concentrations of a series of inorganic and radionuclide analytes to general geographic setting and sediment texture. Significant differences exist between results from the north and south sides of Mesita del Buey, with analyte concentrations being generally higher to the north. These differences probably result primarily from variations in background levels in the source materials for the sediments, perhaps reflecting finer particle sizes and/or better developed soils on the north side of the mesa.
\end{abstract}

\section{INTRODUCTION}

This report presents a statistical evaluation of results from Los Alamos National Laboratory (LANL) Environmental Restoration (ER) Project sediment sampling activities that were conducted in 1994 along a series of drainages below material disposal areas (MDAs) at Technical Area (TA) 54 (LANL, 1996). The 1994 investigation was intended to evaluate potential contaminant transport by surface water from the TA-54 MDAs. It was designed to complement ongoing surveillance sampling of active channel sediments and storm water by focusing on historical sediment deposits, including deposits that might predate the surveillance sampling. Sampling was also designed to encompass the range of sediment texture (grain size) that occurs along each drainage.

Here we focus on the variations in analyte concentrations in 71 sediment samples and on the relationship between these variations and the topographic setting and sediment texture. The observed variation reflects both the nature and source of contamination within each basin and also possible differences in background concentrations between basins.

\section{GEOMORPHIC SETTING}

Sediment samples analyzed in this study were collected from a series of small drainage basins on the north and south sides of Mesita del Buey that receive runoff from the MDAs at TA-54 and drain into Cañada del Buey and Pajarito Canyon, respectively (Figs. 1 and 2). Basin length ranges from about 0.2 to $0.6 \mathrm{~km}$. Basins draining south and northeast are the largest, including some that contain second-order channels, but many of the basins draining north are small and consist of relatively unincised canyon walls.

The source for the sampled sediment includes units $1 \mathrm{v}$ and 2 of the Tshirege Member of the Bandelier Tuff, soils and sedimentary deposits within each basin, and fill material associated with operations at TA-54. Sampled geomorphic settings include local areas of sediment deposition along channels that are confined within banks, particularly areas behind channel obstructions (such as trees, logs, and rocks), and small fan lobes associated with braided channels (Fig. 3a). Sampled areas also include larger fans that have been deposited on the canyon floors, where relatively coarse sediments (coarse to medium sand and gravel) are 


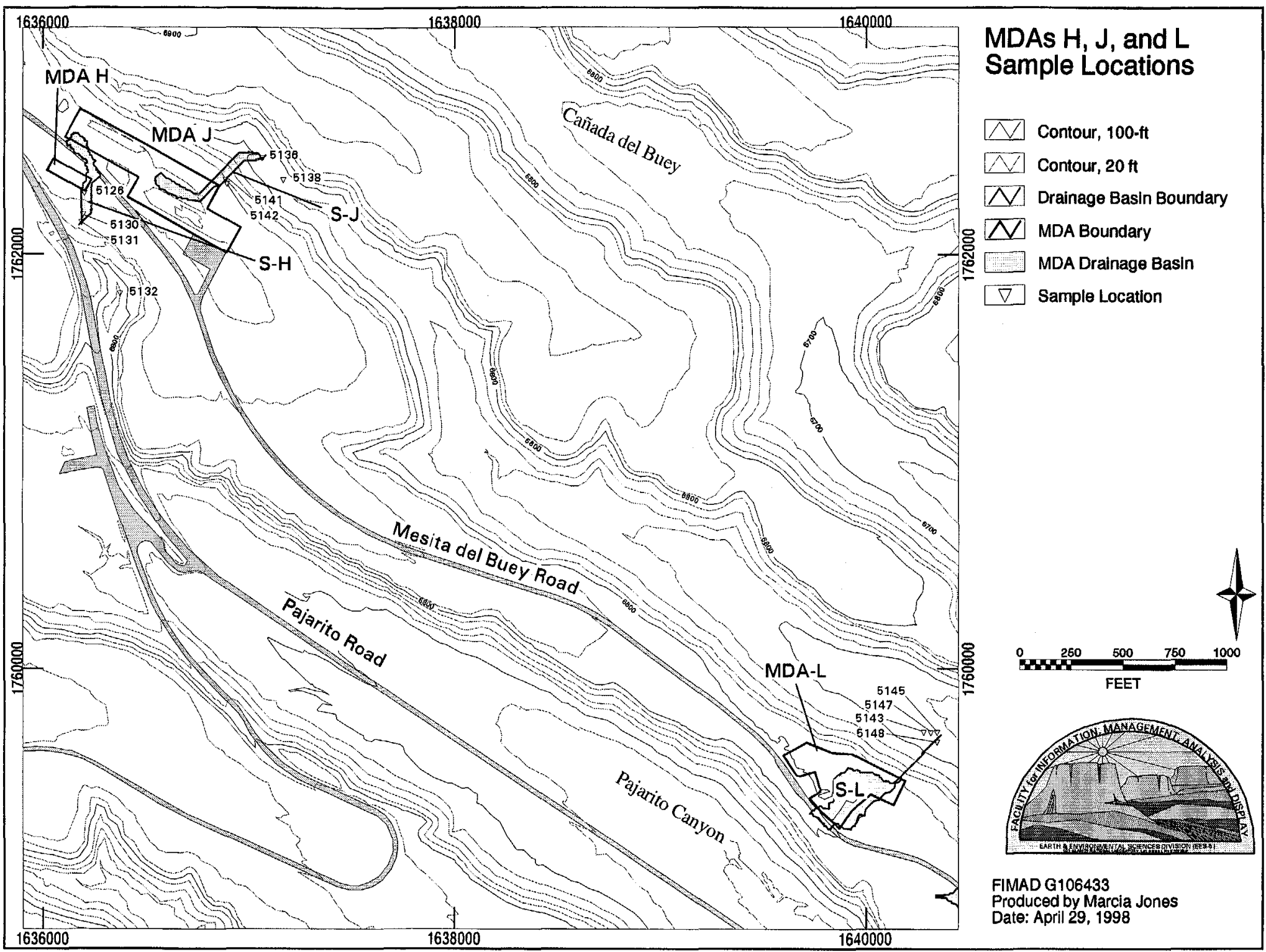

Fig. 1. Drainage basins and sediment sample locations at MDAs $H, J$, and $L, T A-54$. Drainage basins calculated from topographic contours, and actual drainage areas differ because of low berms and shallow ditches on mesa top and diffuse, braided channels in canyons. 


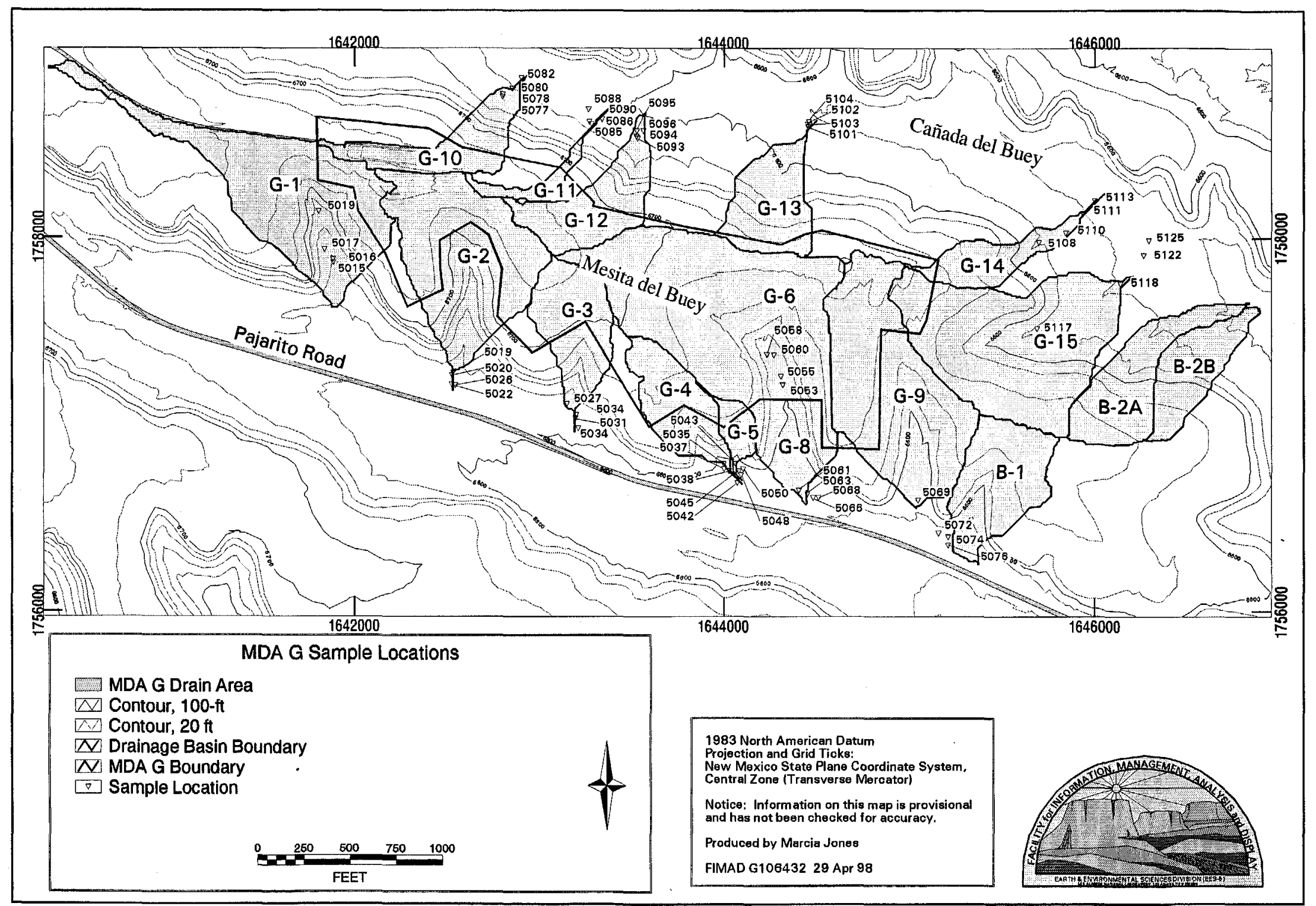

Fig. 2. Drainage basins and sediment sample locations at MDA G, TA-54. Drainage basins calculated from topographic contours, and actual drainage areas differ because of low berms and shallow ditches on mesa top and diffuse, braided channels in canyons. 
found on the upper part of fans, while finer sediments (fine sand, silt, and clay) are carried to the lower part of the fans (Fig. 3b).

\section{SAMPLING AND ANALYSIS}

The 71 sediment samples analyzed for metals and radioisotopes are listed in Table 1 by drainage basin, and sample locations are shown in Figs. 1

a)

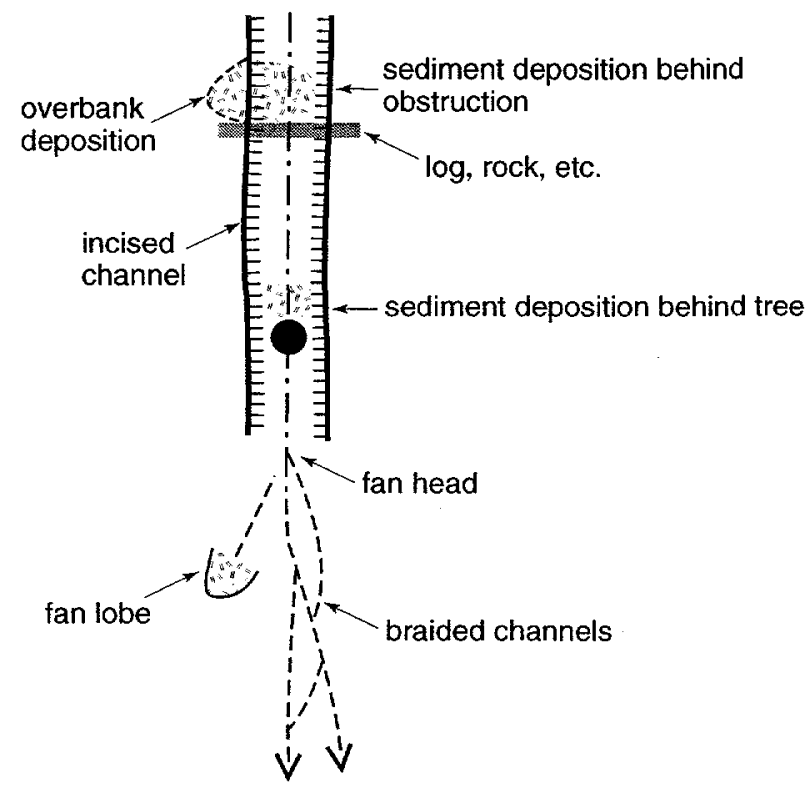

b)

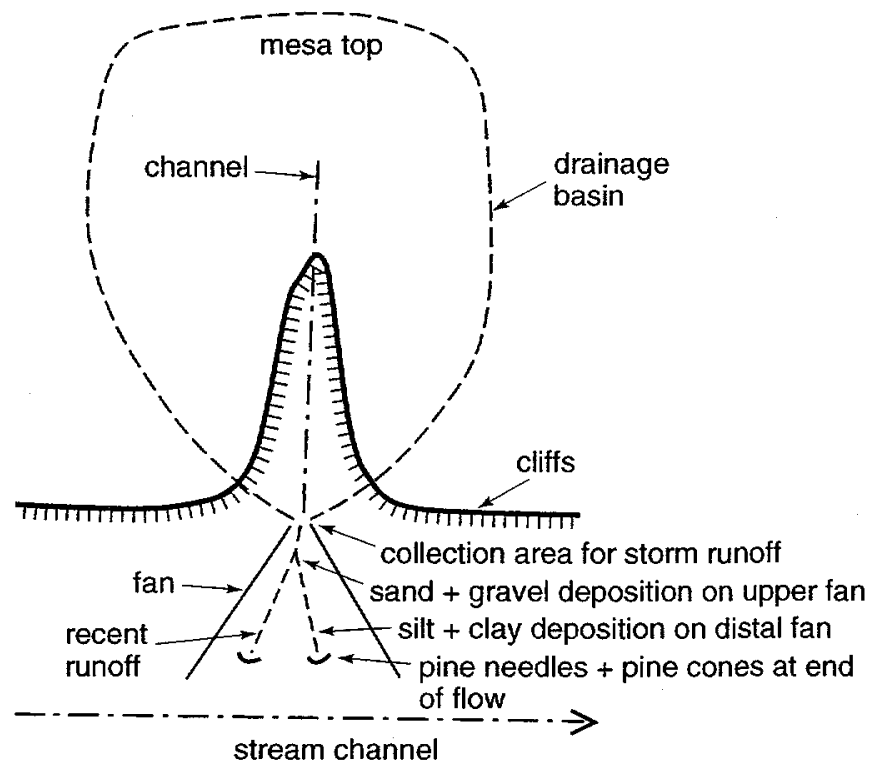

Fig. 3. Geomorphic characteristics of drainage basins at TA-54, illustrating the setting of sediment sample sites. a) Some common depositional areas along channels. b) Typical drainage basin on the south side of MDA $G$, with a young fan. and 2. The field strategy for the 1994 ER study was to identify the most likely historic sediment deposition areas within each drainage basin, based on the geomorphic characteristics of the basin. Within these areas of historical deposition, samples were screened for radioactivity in order to identify areas, if any, of radioactive contamination from the associated MDA. However, this attempt to bias the selection of samples for laboratory analysis was largely unsuccessful because of high detection limits and other method problems with the screening; among the selected samples there is no correlation between the screening and laboratory results. As a result, the four to five samples selected from each drainage basin can be considered to be unbiased representatives of the geomorphic settings and historic sediment deposits found to the north and south of Mesita deI Buey.

Contaminant concentrations may also vary with the grain size distribution of the deposit, and the selected measurement sites include a range in sediment size to capture the variety of deposits present along each drainage. Most of the individual basins also include both fine- and coarse-grained samples, and the numbers of fine- and coarse-grained samples on the north (Cañada del Buey) and south (Pajarito Canyon) sides of TA-54 are approximately equal.

Metals were analyzed using the Environmental Protection Agency (EPA) SW-846 methods that are customary for investigations intended to produce data for risk assessment (EPA, 1992). In particular, the usual SW-846 sample preparation method involves only a weak acid leach, and this partial digestion method does not extract all of the element that is present in the sample. Thus, inorganic chemical data reported here are generally not comparable to data obtained by the total methods that are often preferred for geochemical studies. However, conclusions about the relative 
Table 1. Summary of Channel Sediment Samples

\begin{tabular}{|c|c|c|c|c|}
\hline \multicolumn{2}{|c|}{ Drainage Basin } & Location & Sample ID & General Sediment Texture \\
\hline \multirow[t]{4}{*}{ South } & \multirow[t]{4}{*}{ G-1 } & 5018 & AAB3139 & coarse (sand, gravel) \\
\hline & & 5015 & AAB3143 & fine (sand, silt) \\
\hline & & 5017 & AAB3150 & coarse (sand, gravel) \\
\hline & & 5016 & AAB 3160 & fine (silt, sand) \\
\hline \multirow[t]{4}{*}{ South } & \multirow[t]{4}{*}{ G-2 } & 5022 & AAB3187 & fine (silt) \\
\hline & & 5019 & AAB3190 & fine (silt) \\
\hline & & 5026 & AAB3195 & fine (silt) \\
\hline & & 5020 & $\mathrm{AAB} 3207$ & fine (silt, sand) \\
\hline \multirow[t]{4}{*}{ South } & \multirow[t]{4}{*}{ G-3 } & 5029 & AAB3120 & coarse (sand, gravel) \\
\hline & & 5027 & AAB3122 & coarse (sand, gravel) \\
\hline & & 5031 & $\mathrm{AAB} 3123$ & coarse (sand) \\
\hline & & 5034 & AAB3126 & fine (silt) \\
\hline \multirow[t]{4}{*}{ South } & \multirow[t]{4}{*}{$\mathrm{G}-4$} & 5035 & AAB3194 & coarse (sand, gravel) \\
\hline & & 5042 & AAB3204 & fine (sand, silt) \\
\hline & & 5037 & $\mathrm{AAB} 3208$ & fine (silt) \\
\hline & & 5038 & AAB 3213 & fine (fine sand) \\
\hline \multirow[t]{4}{*}{ South } & \multirow[t]{4}{*}{ G-5 } & 5050 & $\mathrm{AAB} 3132$ & fine (sand, silt) \\
\hline & & 5043 & AAB 3191 & coarse (medium sand) \\
\hline & & 5048 & AAB 3192 & fine (silt) \\
\hline & & 5045 & AAB3196 & coarse (medium/coarse sand) \\
\hline \multirow[t]{5}{*}{ South } & \multirow[t]{5}{*}{ G-6 } & 5055 & $\mathrm{AAB} 3133$ & coarse $($ sand) \\
\hline & & 5058 & $\mathrm{AAB} 3147$ & coarse (sand) \\
\hline & & 5053 & $\mathrm{AAB} 3173$ & coarse $($ sand) \\
\hline & & 5060 & AAB3180 & coarse $($ sand $)$ \\
\hline & & 5055 & $\mathrm{AAB} 3202$ & coarse $($ sand $)$ \\
\hline \multirow[t]{4}{*}{ South } & \multirow[t]{4}{*}{ G-8 } & 5068 & AAB 3118 & fine (fine/medium sand) \\
\hline & & 5066 & $\mathrm{AAB} 3121$ & coarse (sand, gravel) \\
\hline & & 5063 & AAB 3124 & fine (silt) \\
\hline & & 5061 & $\mathrm{AAB} 3128$ & coarse (sand) \\
\hline \multirow[t]{4}{*}{ South } & \multirow[t]{4}{*}{ G-9 } & 5076 & AAB 3106 & fine (silt) \\
\hline & & 5069 & $\mathrm{AAB} 3107$ & coarse (sand, gravel) \\
\hline & & 5074 & $\mathrm{AAB} 3108$ & fine (sand, silt) \\
\hline & & 5072 & AAB3114 & coarse (sand, gravel) \\
\hline \multirow[t]{4}{*}{ North } & \multirow[t]{4}{*}{ G-10 } & 5077 & $\mathrm{AAB} 3170$ & coarse (sand) \\
\hline & & 5082 & AAB3171 & fine (silt, fine sand) \\
\hline & & 5078 & $\mathrm{AAB} 3172$ & coarse (sand, gravel) \\
\hline & & 5080 & AAB 3177 & fine (silt, sand, gravel) \\
\hline \multirow[t]{5}{*}{ North } & \multirow[t]{5}{*}{ G-11 } & 5090 & AAB 3154 & fine (fine/medium sand) \\
\hline & & 5086 & $\mathrm{AAB} 3155$ & coarse (sand) \\
\hline & & 5088 & AAB 3156 & coarse (sand, gravel) \\
\hline & & 5085 & AAB 3158 & coarse (sand, gravel) \\
\hline & & 5085 & $\mathrm{AAB} 3166$ & coarse (sand, gravel) \\
\hline
\end{tabular}


Table 1. (continued)

\begin{tabular}{|c|c|c|c|c|}
\hline \multirow[t]{4}{*}{ North } & \multirow[t]{4}{*}{ G-12 } & 5095 & AAB3157 & fine (sand, silt) \\
\hline & & 5093 & AAB3159 & coarse (sand) \\
\hline & & 5094 & AAB3161 & coarse (sand, gravel) \\
\hline & & 5096 & $\overline{\mathrm{AAB} 3164}$ & coarse (sand, gravel) \\
\hline \multirow[t]{4}{*}{ North } & \multirow[t]{4}{*}{ G-13 } & 5103 & AAB3163 & fine (silt, sand, gravel) \\
\hline & & 5102 & AAB3168 & coarse (sand, gravel) \\
\hline & & 5104 & AAB3169 & fine (silt, sand, gravel) \\
\hline & & 5101 & AAB3178 & coarse (medium/coarse sand) \\
\hline \multirow[t]{4}{*}{ North } & \multirow[t]{4}{*}{ G-14 } & 5111 & $\mathrm{AAB} 3116$ & coarse (sand) \\
\hline & & 5108 & $\mathrm{AAB} 3117$ & fine (sand, gravel, silt) \\
\hline & & 5110 & AAB3127 & fine (sand, gravel, silt) \\
\hline & & 5113 & AAB3167 & fine (fine sand) \\
\hline \multirow[t]{5}{*}{ North } & \multirow[t]{5}{*}{ G-15 } & 5117 & AAB3109 & fine (fine sand, silt) \\
\hline & & 5122 & AAB3110 & fine (silt, fine sand) \\
\hline & & 5118 & $\overline{A A B} 3111$ & fine (silt, fine sand) \\
\hline & & 5122 & $\mathrm{AAB} 3112$ & fine (silt, fine sand) \\
\hline & & 5125 & AAB3113 & fine (silt) \\
\hline \multirow[t]{4}{*}{ South } & \multirow[t]{4}{*}{ S-H } & 5130 & AAB3219 & coarse (sand, gravel) \\
\hline & & 5132 & AAB3131 & coarse (sand) \\
\hline & & 5126 & AAB3142 & fine (silt) \\
\hline & & 5131 & AAB3175 & coarse (sand, gravel) \\
\hline \multirow[t]{4}{*}{ North } & \multirow[t]{4}{*}{ S-J } & 5141 & $\mathrm{AAB} 3130$ & coarse (sand, gravel) \\
\hline & & 5136 & AAB3151 & coarse (sand, gravel) \\
\hline & & 5142 & AAB3162 & coarse (sand) \\
\hline & & 5138 & AAB3174 & coarse (sand, gravel) \\
\hline \multirow[t]{4}{*}{ North } & \multirow[t]{4}{*}{ S-L } & 5143 & $\overline{\mathrm{AAB} 3134}$ & coarse (sand, gravel) \\
\hline & & 5148 & AAB3138 & coarse (sand, gravel) \\
\hline & & 5147 & AAB3149 & fine (sand, silt) \\
\hline & & 5145 & AAB3179 & coarse (sand, gravel) \\
\hline
\end{tabular}

concentrations associated with different sediment grain sizes or basins may be drawn from these results.

The radioisotopes considered in this report were measured by alpha spectrometry, and the corresponding sample preparation method requires total digestion of the samples.

\section{STATISTICAL EVALUATION OF THE RESULTS}

Since the preparation of the original report on this study (LANL, 1996), more data on the natural background geochemistry of sediments on the
Pajarito Plateau have been collected (McDonald et al., 1997; Ryti et al., 1998). New and more representative background values for both metals and naturally occurring radionuclides are presented by McDonald et al. (1997) and Ryti et al. (1998). Only a handful of observations from the 71 sediment samples exceed these background values. These include two samples with lead concentrations slightly above background levels in the drainage from MDA $\mathrm{H}$ (basin $\mathrm{S}-\mathrm{H}$ ), chromium in one sample from basin G-12, cadmium in one sample from G-14, and barium, magnesium, and iron in samples from G-15. Apart from these scattered "hits" (none of which exceed the background values for sediments reported by 
McDonald et al. (1997) and Ryti et al. (1998) by as much as a factor of three), the results from these samples appear to be representative of background levels for sediments of the Pajarito Plateau.

The measured isotopes of radium, thorium, and uranium are within background ranges and appear to be in approximate secular equilibrium. In particular, there is no evidence of contamination by enriched, natural, or depleted uranium. There are, however, several samples with elevated levels of ${ }^{241} \mathrm{Am},{ }^{238} \mathrm{Pu}$, and ${ }^{239,240} \mathrm{Pu}$. Unlike the generally normal distributions of the data for inorganic chemicals and naturally occurring radionuclides, the distributions of the data for these three isotopes tend to be skewed with long upper tails.
Tables 2, 3, and 4 summarize the results of statistical tests that were applied to the data. The following hypotheses were evaluated:

Hypothesis \#1. Analytical results from finegrained samples are systematically higher than those for coarse-grained samples, as suggested by previous studies such as McDonald et al. (1997) and Reneau et al. (1998).

Hypothesis \#1 was tested using 1) all 71 samples, 2) only samples from the north side of Mesita del Buey, and 3) only samples from the south side. Tables 2, 3, and 4 summarize the results for the tests using all 71 samples in the columns headed "Fine>Coarse?," and test results based on subsets

Table 2. Summary of Statistical Tests Using Inorganic Analytical Results

\begin{tabular}{|c|c|c|c|c|}
\hline Element & $\begin{array}{l}\text { Number of } \\
\text { results } \\
\text { above DL }\end{array}$ & $\begin{array}{l}\text { Number of } \\
\text { outliers } \\
\text { (a) }\end{array}$ & $\begin{array}{c}\text { Fine }>\text { Coarse? } \\
\text { (P-value) } \\
(a, b)\end{array}$ & $\begin{array}{c}\text { North }>\text { South? } \\
\text { (P-value) } \\
(a, b)\end{array}$ \\
\hline Aluminum & 71 & 0 & $<0.001$ & $<0.001$ \\
\hline Arsenic & 3 & $\overline{\mathrm{NA}}$ & $\mathrm{NA}$ & $\mathrm{NA}$ \\
\hline Barium & 53 & 0 & 0.001 & $<0.001$ \\
\hline Beryllium & 5 & $\overline{\mathrm{NA}}$ & $\mathrm{NA}$ & NA \\
\hline Cadmium & 2 & 1 & $\mathrm{NA}$ & NA \\
\hline Calcium & 53 & 1 & 0.002 & 0.016 \\
\hline Chromium & 57 & 1 & 0.013 & $<0.001$ \\
\hline Cobalt & 2 & $\mathrm{NA}$ & NA & $\mathrm{NA}$ \\
\hline Copper & 17 & 0 & 0.046 & 0.553 \\
\hline Iron & 71 & 1 & 0.020 & $<0.001$ \\
\hline Lead & 71 & 2 & 0.001 & 0.023 \\
\hline Magnesium & 28 & 0 & 0.016 & 0.001 \\
\hline Manganese & 70 & 0 & 0.002 & 0.014 \\
\hline Mercury & 1 & NA & $\mathrm{NA}$ & NA \\
\hline Nickel & 3 & NA & $\mathrm{NA}$ & NA \\
\hline Potassium & 20 & 0 & 0.008 & 0.019 \\
\hline Silver & 1 & $\mathrm{NA}$ & $\mathrm{NA}$ & $\mathrm{NA}$ \\
\hline Sodium & 1 & $\overline{\mathrm{NA}}$ & $\mathrm{NA}$ & $\mathrm{NA}$ \\
\hline Vanadium & 18 & 0 & 0.137 & $<0.001$ \\
\hline Zinc & 71 & 0 & 0.002 & 0.001 \\
\hline
\end{tabular}

(a) NA indicates insufficient data (too many below-detection results) to test for outliers or significant differences.

(b) P-values in this table indicate results for statistical tests performed using all data in the named groups except outliers identified in Table 5. 
Table 3. Summary of Statistical Tests for Naturally Occurring Radioisotopes

\begin{tabular}{|c|c|c|c|c|}
\hline \hline Isotope & $\begin{array}{c}\text { Number of } \\
\text { results above } \\
\text { DL }\end{array}$ & $\begin{array}{c}\text { Number } \\
\text { of } \\
\text { outliers }\end{array}$ & $\begin{array}{c}\text { Fine>Coarse? } \\
\text { (P-value) } \\
(\mathrm{a})\end{array}$ & $\begin{array}{c}\text { North>South? } \\
\text { (P-value) } \\
\text { (a) }\end{array}$ \\
\hline \hline${ }^{226} \mathbf{R a}$ & 71 & 0 & 0.016 & 0.091 \\
\hline${ }^{228} \mathbf{T h}$ & 71 & 0 & 0.001 & 0.035 \\
\hline${ }^{230} \mathbf{T h}$ & 71 & 0 & $<0.001$ & 0.036 \\
\hline${ }^{232} \mathbf{T h}$ & 71 & 0 & 0.001 & 0.063 \\
\hline${ }^{234} \mathbf{U}$ & 71 & 0 & $<0.001$ & 0.102 \\
\hline${ }^{235} \mathbf{U}$ & 71 & 0 & 0.017 & 0.114 \\
\hline${ }^{238} \mathbf{U}$ & 71 & 0 & 0.001 & 0.074 \\
\hline
\end{tabular}

(a) P-values in this table indicate results for tests performed using all data in the named groups.

Table 4. Summary of Statistical Test Results for Antropogenic (Fallout) Radioisotopes

\begin{tabular}{|c|c|c|c|c|}
\hline Isotope & $\begin{array}{c}\text { Number of } \\
\text { results } \\
\text { above DL }\end{array}$ & $\begin{array}{c}\text { Number } \\
\text { of } \\
\text { outliers }\end{array}$ & $\begin{array}{c}\text { Fine>Coarse? } \\
\text { (P-value) } \\
\text { (a) }\end{array}$ & $\begin{array}{c}\text { North>South? } \\
\text { (P-value) } \\
\text { (b) }\end{array}$ \\
\hline${ }^{\mathbf{2 4 1} \mathbf{A m}}$ & 71 & 0 & 0.005 & 0.065 \\
\hline${ }^{137} \mathbf{C s}$ & 38 & 0 & 0.070 & 0.050 \\
\hline${ }^{238} \mathbf{P u}$ & 71 & 2 & 0.164 & 0.073 \\
\hline${ }^{239,240} \mathbf{P u}$ & 71 & 2 & 0.040 & 0.010 \\
\hline
\end{tabular}

(a) P-values in this column indicate results for tests performed using all data except outliers identified in Table 5.

(b) P-values in this column indicate results for tests performed using data from the fine-grained samples only, excluding outliers identified in Table 5.

of samples from the north and south side of Mesita del Buey are discussed in the text.

Hypothesis \#2. Analytical results for samples from the north side of Mesita del Buey are systematically higher than those for samples from the south side. McDonald et al. (1997) found at most small differences between canyons in their studies, but plots of the TA-54 sediment data suggest some systematic differences.

Hypothesis \#2 was tested using 1) all 71 samples, 2 ) only fine-grained samples, and 3 ) only coarsegrained samples. Tables 2 and 3 summarize the results for the tests using all samples in the columns headed "North $>$ South?," and Table 4 presents results for fine-grained samples in the corresponding column. Test results based on other subsets of the data are discussed in the text.

All statistical comparisons were made using the nonparametric Wilcoxon test with the Gehan modification for nondetects, which is further described in the Appendix. A few outliers were eliminated before performing the statistical tests, although some values above background were retained. The numbers of outliers are indicated in Tables 2, 3, and 4, and the specific outliers are listed in Table 5. Statistical results are reported in Tables 2,3 , and 4 in terms of the significance level or " $P$ value" of the computed test statistic. Traditionally, a P-value of less than 0.01 is considered a highly significant result (one that would be obtained by chance less than one time in a hundred); $P$-values of up to 0.1 indicate results that might occur by chance up to one time in ten; and P-values greater 
than 0.1 are generally considered too large to indicate a significant difference between the two populations being compared.

For 12 of the 20 elements reported from the inorganic chemical analyses, there are enough data above the method detection limit (DL) to perform statistical comparisons. The results of these statistical tests reaffirm the observations of earlier studies by confirming the preferential association of most elements with the fine fraction of the sediments. The results for the tests of Hypothesis \#1 based on all of the samples were significant at the $5 \%$ level or better for eleven of the twelve elements. The exception (vanadium) is an element for which virtually all of the detected results are on the north side of Mesita del Buey; only two of the eighteen detected results were on the south side. When only samples from the north side are used, the test for vanadium gives a P-value of 0.086 , despite the smaller sample size (which makes it more difficult to achieve a highly significant result).

The distributions illustrated by the box plot for iron in Figure 4 are typical. (Box plots such as Figure 4 are explained in the Appendix.) As suggested by Figure 4 , the association with the fine fraction is generally true on both the north and south sides of Mesita del Buey. Exceptions were noted for zinc on the north side and for copper and potassium (and vanadium, here almost entirely undetected) on the south side. Potassium is another element with significantly larger numbers of nondetect results on the south side than the north.
As Figure 4 shows, there are also significant differences overall between the north and south sides of Mesita del Buey (Hypothesis \#2). For eleven of the twelve metallic elements (all except copper), the difference between samples from the north-draining basins (in Cañada del Buey) and those from the south-draining basins (in Pajarito Canyon) was statistically significant at the 5\% level or better. That is, sediments from the Cañada del Buey side appear to be significantly enriched, by comparison with those from the south side, with respect to both major and several minor elements.

In view of the fact that fine- and coarse-grained samples were collected in about equal numbers on each side of the mesa, this result appears to be independent of the fine- versus coarse-grained contrast discussed earlier. In general, the contrasts between north and south-side samples hold for coarse-textured as well as fine-textured samples, although the difference fails to be statistically significant (at the $10 \%$ level) for potassium in coarse-textured samples. The P-value is also slightly greater than $10 \%(0.106)$ for zinc in finetextured samples.

Table 3 summarizes test results for the naturally occurring radioisotopes. There are no belowdetection-limit results for the seven isotopes of radium, thorium, and uranium. Like the inorganic chemicals, all of these isotopes are significantly associated with the fine fraction, as are all of the anthropogenic radioisotopes with sufficient data above the detection level (Table 4) except ${ }^{238} \mathrm{Pu}$.

Table 5. Outliers in Channel Sediment Samples

\begin{tabular}{|c|c|c|c|c|}
\hline \multicolumn{2}{|c|}{ Drainage Basin } & Sample ID & Analyte & Value \\
\hline South & G9 & AAB3106 & ${ }^{239} \mathrm{Pu}$ & $0.909 \mathrm{pCi} / \mathrm{g}$ \\
\cline { 2 - 5 } & $\mathbf{G 9}$ & $\mathrm{AAB} 3108$ & ${ }^{239} \mathrm{Pu}$ & $0.858 \mathrm{pCi} / \mathrm{g}$ \\
\cline { 2 - 5 } & $\mathbf{G 4}$ & $\mathrm{AAB} 3194$ & $\mathrm{Ca}$ & $6370 \mathrm{mg} / \mathrm{kg}$ \\
\cline { 2 - 5 } & $\mathbf{G 5}$ & $\mathrm{AAB} 3191$ & ${ }^{238} \mathrm{Pu}$ & $0.576 \mathrm{pCi} / \mathrm{g}$ \\
\cline { 2 - 5 } & $\mathbf{S H}$ & $\mathrm{AAB} 3129$ & $\mathrm{~Pb}$ & $21.3 \mathrm{mg} / \mathrm{kg}$ \\
\cline { 2 - 5 } & $\mathbf{S H}$ & $\mathrm{AAB} 3175$ & $\mathrm{~Pb}$ & $19.9 \mathrm{mg} / \mathrm{kg}$ \\
\hline North & $\mathbf{G 1 2}$ & $\mathrm{AAB} 3159$ & $\mathrm{Cr}$ & $17.9 \mathrm{mg} / \mathrm{kg}$ \\
\cline { 2 - 5 } & $\mathbf{G 1 3}$ & $\mathrm{AAB} 3169$ & ${ }^{238} \mathrm{Pu}$ & $1.483 \mathrm{pCi} / \mathrm{g}$ \\
\cline { 2 - 5 } & $\mathbf{G 1 5}$ & $\mathrm{AAB} 3109$ & $\mathrm{Fe}$ & $39,000 \mathrm{mg} / \mathrm{kg}$ \\
\hline
\end{tabular}




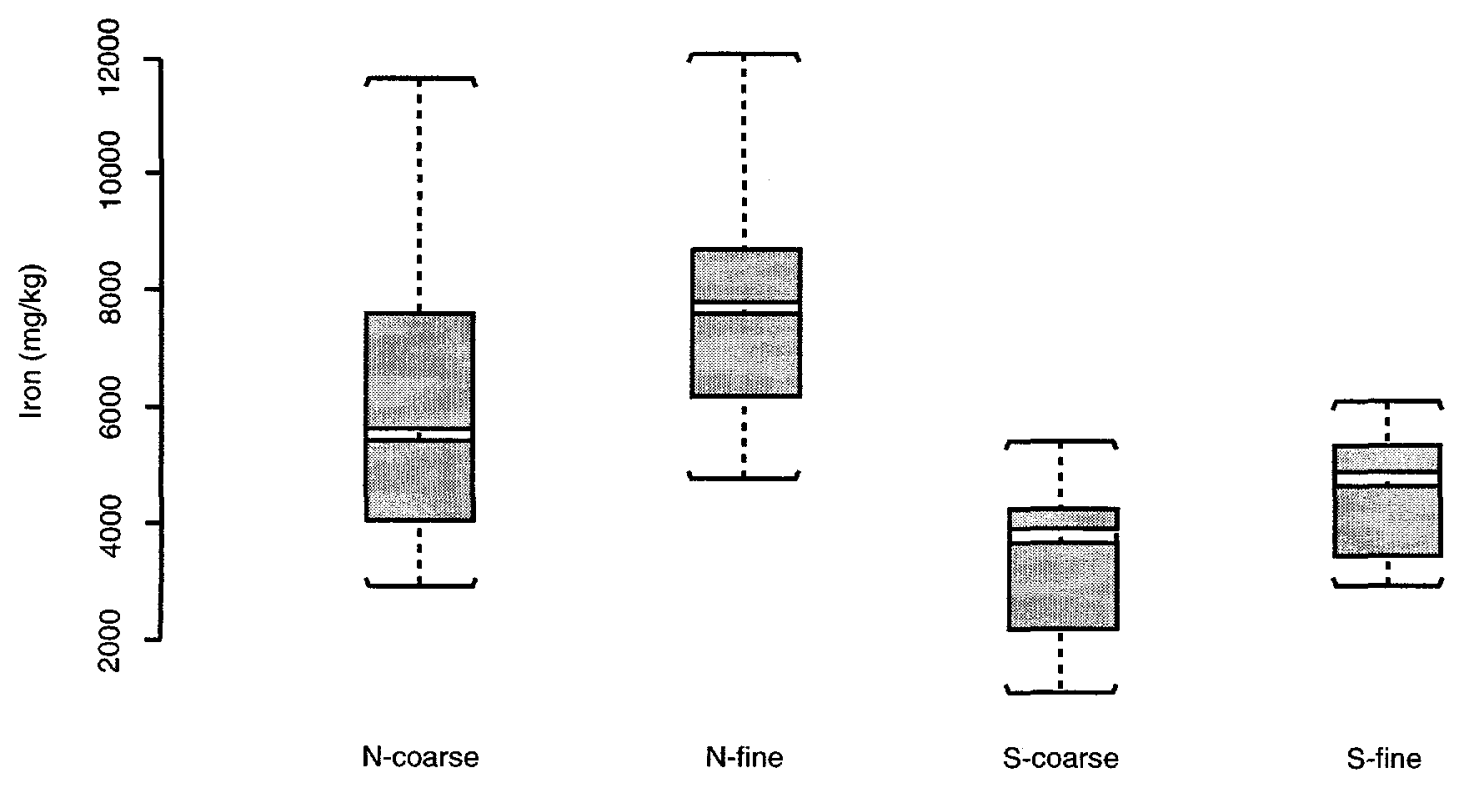

Fig. 4. Box plots of the distribution of iron in sediment samples.

By contrast with the inorganic chemical results shown in Table 2, however, the association of the naturally occurring radioisotopes with the fine sediments appears to hold strongly only on the south side of Mesita del Buey. Most of the statistical tests using only samples from the north side of the mesa fail to achieve the $10 \%$ significance level, although the $\mathrm{P}$-values remain below 0.2 . (Exceptions are ${ }^{226} \mathrm{Ra}$ at $\mathrm{P}=0.012$ and ${ }^{230} \mathrm{Th}$ at $\mathrm{P}=$ 0.08.) The plot of ${ }^{238} \mathrm{U}$ in Figure 5 is typical of these radioisotopes.

As shown in Figure 5 and Table 3, north/south contrasts similar to those for metals are also found for naturally occurring radioisotopes. In contrast to the results for inorganic chemicals, however, these differences appear to be due entirely to the concentrations in coarse-grained sediments; the significance levels of the tests using only coarsegrained sediments is lower than shown in the last column of Table 3 for all of the isotopes of thorium and uranium. Hypothesis \#2 must be rejected for these isotopes in fine-grained sediments. Only the result for ${ }^{226} \mathrm{Ra}$ appears to be due to data from the fine-grained samples; the P-value for the north/ south comparison for this isotope is 0.058 for finegrained samples but slightly greater than 0.2 for coarse-grained samples.
The anthropogenic radioisotopes ${ }^{241} \mathrm{Am},{ }^{137} \mathrm{Cs}$, and ${ }^{239.240} \mathrm{Pu}$ behave very differently from the naturally occurring isotopes. For these anthropogenic radioisotopes, reported at levels that at least in part represent releases from MDA G, the observed association with fine sediments is a consequence of a strong difference in fine- versus coarse-grained samples from the north side of the mesa, as seen for example in Figure 6 for ${ }^{239,240} \mathrm{Pu}$. Hypothesis \#1 must be rejected for the south side of Mesita del Buey. Moreover, north/south differences are found only in the fine-grained samples, as reported in Table 5. Hypothesis \#2 must be rejected for the coarse-grained samples and for all samples combined.

\section{DISCUSSION}

McDonald et al. (1997) found relatively few differences between canyons in their study, so the highly significant differences found in this study between sediments on the north and south sides of Mesita del Buey require some explanation. One possibility is that, despite the lack of observations above background among the metals and naturally occurring radionuclides, these differences are a subtle indication of more contaminant migration 


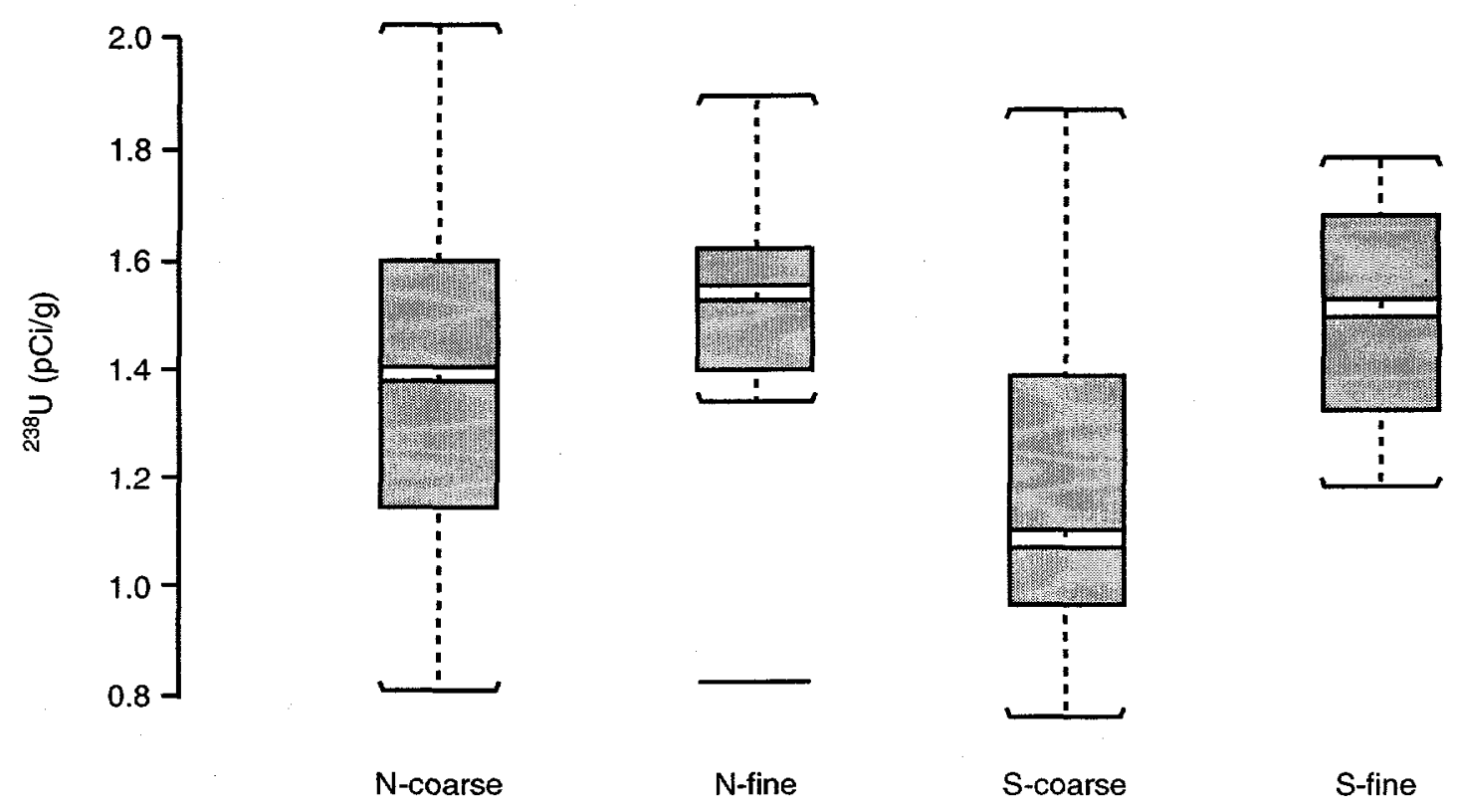

Fig. 5. Box plots of the distribution of ${ }^{238} U$ in sediment samples.

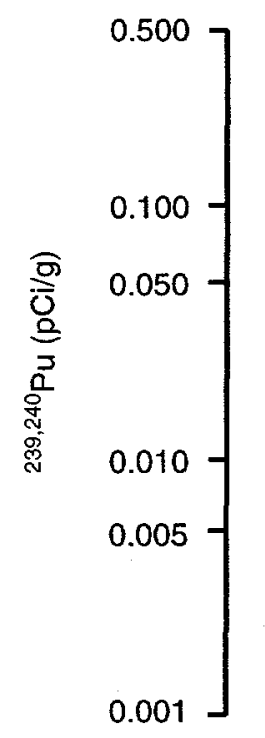

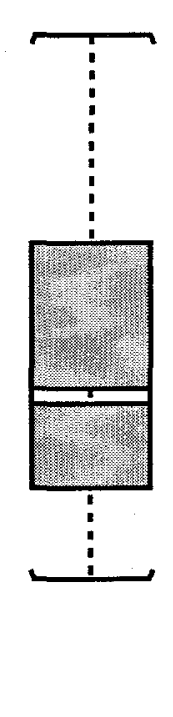

$\mathrm{N}$-coarse

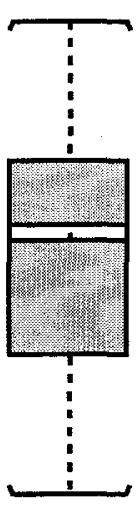

$\mathrm{N}$-fine

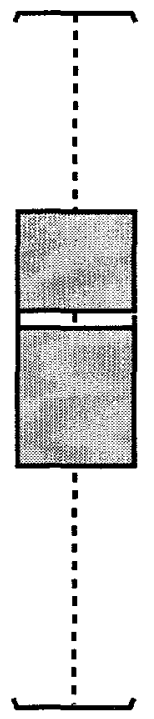

S-coarse

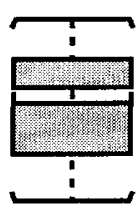

S-fine

Fig. 6. Box plots of the distribution of ${ }^{239,240} \mathrm{Pu}$ in sediment samples (note logarithmic scale).

to the north than to the south or a higher percentage of the young sediments to the north being derived from contaminated areas. This hypothesis is consistent with the fact that the same pattern is found in the anthropogenic radionuclides. However, the north-south contrast is apparent in almost all of the naturally occurring analytes, and it seems very unlikely that all of these analytes would be present as widespread contaminants across the MDAs without also being more frequently detected above background. We thus conclude that these north-south differences for inorganic chemicals and naturally occurring radionuclides indicate primarily variations in 
background levels in the source materials providing sediment.

A second possibility is that the sediment samples on the north side typically have higher percentages of fine particles within a given grain size class (coarse versus fine) relative to the south side. Sampled drainages to the north typically have smaller basins than those to the south, which could result in smaller average runoff events and less effective winnowing of fines from the channels. It is also possible that the fine-grained component to the north typically contains more silt and clay relative to fine sand, perhaps reflecting differences in source material. This hypothesis cannot be tested without more detailed particle size data.

A third possibility is that the source for the sediments on the north side typically includes a higher portion of soils with stronger soil development than to the south. Background soil data from the Pajarito Plateau have demonstrated that better developed soils have significantly more iron, aluminum, and trace metals than weakly developed soils (Longmire et al., 1996; McDonald et al., 1996). The correlation between the trace and major elements (particularly iron) found in the TA54 sediment samples mirrors the correlations found in other soil studies. This hypothesis is also supported by field observations that bare tuff is much more widely exposed on the south side of Mesita del Buey relative to the north, so that a larger portion of the source area for sediments to the south may consist of either freshly eroded tuff or weakly developed soils derived from tuff. Because of the larger runoff areas generally contained within disturbed areas at the MDAs in the south-draining basins, sediment from these basins may also contain a higher percentage of eroded fill material that is more similar to unweathered parent materials than to soils with pedogenic alteration. In connection with this observation, it is interesting that the data summarized by Ryti et al. (1998) suggest that while the concentrations of most inorganic elements are higher in soil than in the Tshirege Member of the Bandelier Tuff, the reverse is true for zinc, potassium, uranium, and thorium.
Thus, the greater exposure of tuff on the south side of Mesita del Buey may account for the relatively weak north/south contrasts for uranium, thorium, zinc, and potassium as compared with the remaining inorganic elements. These elements also do not show such strong correlations with iron and aluminum as many of the other inorganic elements.

Finally, as observed in the preceding section, the geographic and sedimentologic distribution of anthropogenic isotopes that are at least in part related to releases at the MDAs differs somewhat from that present in analytes that most likely represent background variations. These differences are probably related in part to the mixing of data from separate drainage basins with differing contributions from the MDAs for the purpose of statistical analysis. In particular, the two highest analyses for ${ }^{239.240} \mathrm{Pu}$, excluded from statistical analysis as outliers, actually came from finegrained sediments in a south-side basin (G-9); this somewhat confounds the conclusions implied by Table 4 and Figure 6, which are based on the bulk of the ${ }^{239,240} \mathrm{Pu}$ data. The analytical results may also reflect spatial variations in erosion of contaminants originally deposited on the surface (whether from global fallout or airborne from more local sources within the MDAs), an effect that would not be seen in samples of native, relatively homogeneous material.

\section{ACKNOWLEDGMENTS}

This work was supported by the Los Alamos Environmental Restoration Project as part of the RCRA Facility Investigation (RFI) site characterization activities for TA-54. We thank Diana Hollis, Don Krier, and Cheryl Rofer for their support; John Carney for assistance in initial selection of sample sites; Marcy Backsen, Linda Causey, Mike Ebinger, Ralph Jennings, Don Krier, and Michelle Morgenstern for their contributions to the original RFI report; Mable Amador for editing; Lanny Piotrowski for compositing of the final report; and Kay Birdsell for helpful review comments. 


\section{REFERENCES}

EPA(US Environmental Protection Agency), 1992, Test Methods for Evaluating Solid Waste, Physical/ Chemical Methods, SW-846, Third Edition, Final Update 1, Office of Solid Waste and Emergency Response, Washington, D.C.

LANL (Los Alamos National Laboratory), 1996, RFI Report for Channel Sediment Pathways from MDAs G, H, J, and L, TA-54: Los Alamos National Laboratory report LA-UR-96-110, Los Alamos, New Mexico.

Longmire, P. A., Reneau, S. L., Watt, P. M., McFadden, L. D., Gardner, J. N., Duffy, C. J., and Ryti, R. T., 1996, Natural Background Geochemistry, Geomorphology, and Pedogenesis of Selected Soil Profiles and Bandelier Tuff, Los Alamos, New Mexico: Los Alamos National Laboratory report LA-12913-MS, Los Alamos, New Mexico, 176 pp.

McDonald, E. V., Longmire, P. A., Watt, P. M., Ryti, R. T., and Reneau, S. L., 1996, Natural Major and Trace Element Background Geochemistry of Selected Soil Profiles, Los Alamos, New Mexico, in Goff, F., Kues, B. S., Rogers, M. A., McFadden, L. D., and Gardner, J. N., Eds., The Jemez Mountains Region: New Mexico Geological Society Forty-Seventh Annual Field Conference Guidebook, pp. 375-382.

McDonald, E. V., Ryti, R. T., Reneau, S. L., Carlson, D., and Harris, J., 1997, Natural Background Geochemistry of Sediments, Los Alamos National Laboratory: Environmental Restoration Project ID 55532, Los Alamos National Laboratory, Los Alamos, New Mexico.

Reneau, S. L., Campbell, K., Longmire, P., and McDonald, E., 1998, Geochemistry of Background Sediment Samples at Technical Area 39, Los Alamos National Laboratory: Los Alamos National Laboratory report LA-13535-MS, Los Alamos, New Mexico, 26 pp.
Ryti, R. T., Longmire, P. A., Broxton, D. E., Reneau, S. L., and McDonald, E. V., 1998, Inorganic and Radionuclide Background Data for Soils, Canyon Sediments, and Bandelier Tuff at Los Alamos National Laboratory: Los Alamos National Laboratory report LA-UR-98-4847, Los Alamos, New Mexico.

\section{APPENDIX. STATISTICAL METHODS}

Box plots. A single box plot provides a quick visual summary of the distribution of a set of values, indicating its symmetry or skewness and whether it is tightly clustered around its central value or has long tails at one or both ends. The central rectangle (or "box") covers the middle $50 \%$ of the distribution (see Fig. A-1). Within this middle 50\%, the location of the median or 50th percentile is indicated by a line drawn across the box. For a symmetric distribution, this line would fall midway between the ends of the box; when the line falls closer to one end than the other, this indicates that the distribution is skewed. "Whiskers" are drawn from each end of the box extending to the largest and smallest values in the data set that do not lie at a distance of more than 1.5 times the interquartile range from the 75 th or 25 th percentile, respectively. Values beyond these extremes appear as outliers relative to the bulk of the data and are plotted individually.

Because a box plot is essentially a one-dimensional plot, two or more of them can be presented on one page, as in Figure A-1 and in Section 4 of this report, permitting quick visual comparisons of two or more distributions.

Comparison of populations. To go beyond such visual comparjsons, there are numerous statistical tests designed to compare two distributions. The best-known of these "two-sample tests" is the Student's t-test, but this test is based on the assumption that the data sets being compared are drawn from normal distributions (in particular, are symmetric and without exceptionally long tails or 


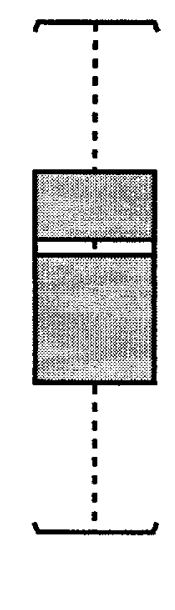

Group 1

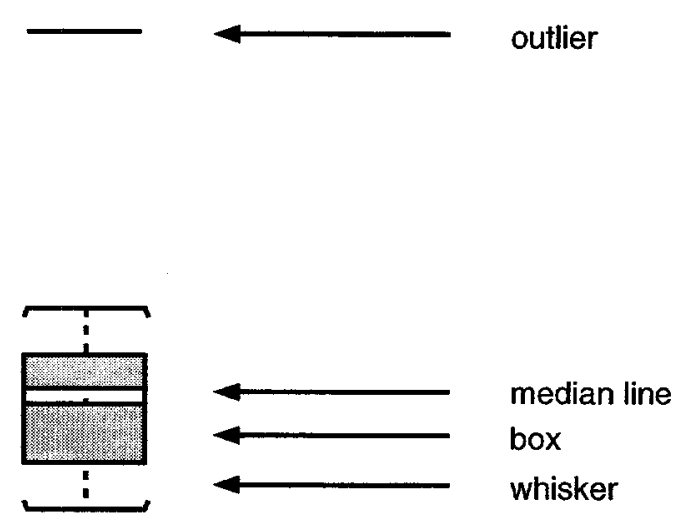

Group 2

Fig. A-1. Schematic components of box plots (arbitrary units).

outliers), although in fact the test is remarkably robust to departures from these assumptions. A nonparametric alternative (that is, an alternative that does not require parametric assumptions such as normality) is the Wilcoxon test, which uses the ranked data. (A ranked data set is one in which the $\mathrm{n}$ actual observations have been replaced by their ranks from 1 to $\mathrm{n}$, with some suitable convention for handling ties. By reducing a data set to a set of ranks, the influence of outliers, skewness, and other departures from normality is greatly reduced.) Both the t-test and the Wilcoxon test are discussed by Gilbert (1987, Chapter 18).

When, as is frequently the case for environmental data, some of the data are "censored" or reported as below a detection level, and when moreover not all of these detection levels are identical, then the Gehan modification to the Wilcoxon test is useful. This procedure for ranking below-detection-level observations together with measured values so that the standard Wilcoxon test can be applied is discussed in detail by Gehan (1965) and Gilbert and Simpson (1990). It was used extensively in Section 4 of this report to accommodate the various types of distributions present in the data.

It is generally true that nonparametric tests are less "powerful" than parametric tests when applied to data sets for which the parametric assumptions in fact hold. This means that they are less likely to detect a significant difference if one exists. However, as shown in Section 4, they identified many statistically significant differences among the data analyzed in this report, so clearly this is not a problem in the present application.

\section{REFERENCES FOR APPENDIX}

Gehan, E. A., 1965, A Generalized Wilcoxon Test for Comparing Arbitrarily Singly-Sensored Samples: Biometrika, v. 52, nos. 1 and 2, pp. 203223.

Gilbert, R. O., 1987, Statistical Methods for Environmental Pollution Monitoring: Van Nostrand Reinhold, New York, 320 pp.

Gilbert, R. O., and Simpson, J. C., 1990, Statistical Sampling and Analysis Issues and Needs for Testing Attainment of Background-Based Cleanup Standards at Superfund Sites, in Proceedings of The Workshop on Superfund Hazardous Waste: Statistical Issues in Characterizing a Site: Protocols, Tools, and Research Needs, Environmental Protection Agency, Arlington, Virginia. 


\section{Los Alamos \\ NATIONAL LABORATORY \\ Los Alamos, New Mexico 87545}

